ferido para as indústrias PRÓLOGO e COMSIP, o Centro de Operação do Sistema (COS), com a LIGHT, e o Centro de Supervisåo de Usinas (CSU), com a Eletrosul. Outro projeto importante na área de eletrônica foi o do Medidor e Registrador de Energia e Demanda, destinada a viabilizar a implantação da tarifa diferenciada no Brasil.

O CEPEL desenvolve uma atividade importante de intercâmbio internacional, além de prestar serviços a outros países, em apoio à política de exportação de bens e serviços do Brasil. Destacam-se os convênios de intercâmbio de informaçōes e complementação de recursos laboratoria is firmado pelo CEPEL com entidades congêneres no exterior, tais como o IREQ (Canadá); CESI (Itália); IIE (México); EPRI (Estados Unidos); CRIEPI (Japão): KEMA (Holanda) e os contratos de venda de servicos assinados com o EPRI, nos Estados Unidos e com a Siemns, na Alemanha, entre outros.

\title{
O balanço energético nacional: o papel da energia elétrica
}

\section{PÉRICLES AMORIM FIGUEIREDO}

Engenheiro da ELETROBRAS. Formado pela Escola de Engenharia da Universidade Federal de Pernambuco, como engenheiro mecânico. tem curso de Pós-Graduação em Engenharia de Produção pela Coppe, Universidade Federal do Rio de Janeiro. Foi secretário de Tecnologia do Ministério das Minas e Energia e coordenou o Comitê de Balanço Energético Nacional e o Comitê de Informaçōes Tecnológicas, no smbito do MME.

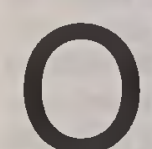

Balanço Energético Nacional (BEN), editado anualmente pelo Ministério das Minas e Energia, apresenta de forma sistemática uma contabilização dos fluxos energéticos no país, evidenciando as relações entre a oferta e a demanda de energia.

Como tal, envolve certas convenções, pelas quais são apropriadas as quantidades de energia, e dentre estas está a extensão da cadeia energética que se pretende mostrar.

Nas versões correntes do BEN, por exemplo, ainda não são computados os rendimentos dos equipamentos de consumo final, segundo os quais uma deter. minada forma de energia, como a eletri. cidade, diesel, álcool, etc., é convertida em energia útil.

Nesse sentido, foi recentemente publicado, pelo Ministério, um Balanço de Energia Útil para o ano de 1983, com base num estudo preliminar realizado pela FDTE (Fundação para o Desenvolvimento Jecnológico de Energia).

Assim, têm-se os seguintes conceitos para o consumo de energia:

- consumo de energia útil - energia efetivamente convertida em força motriz, calor de processo, iluminação, aquecimento direto, ele troquímica, etc.;

- consumo final energético - destinação para fins energéticos de derivados de petróleo, eletricidade, lenha, carvão vegetal, carvão mineral, etc.;

- consumo final - igual ao consumo final energético mais a quantidade de energia contida em produtos que são utilizados em diferentes setores para fins não energéticos (ex.: uso da nafta na petroquimical:
- energia para transformação - produtos energéticos na forma provida pela natureza (petróleo, hidráulico, cana-deaçúcar, lenhal, que através de um Centro de Transformação (destilaria, hidrelétrica, refinaria, etc.) são transformados em formas mais adequadas para manuseio.

Outra convenção utilizada diz respeito às equivalências entre as formas de energia. Na elaboração do BEN é adotada como unidade padrăo a "tonelada equivalente de petróleo - TEP". Então, um energético, como a eletricidade, é medido em termos da quantidade equivalente ao derivado de petróleo necessário para gerar aquela mesma quantidade de eletricidade. Existem outras convenções e uma delas é a de se considerar o conceito teórico de equivalência calórica, segundo a qual se contabilizam as formas de energia pelo calor que elas sejam capazes de gerar, diretamente pela queima, ou indiretamente, através do uso de algum dispositivo de transformação.

Referidas convenções não são escoIhidas arbitrariamente, mas são decorrência da realidade que se deseja evidenciar. Assim, por exemplo, o BEN mostra, de uma forma apropriada, a quantidade de petróleo adicional que se deveria produzir caso se estivesse que gerar a eletricidade exclusivamente à base de derivados de petróleo. Já o emprego do Balanço de Energia Útil é mais indicado para mostrar o esforço necessário para substituição do consumo de petróleo por, exemplificando, hidreletricidade.

Finalmente, ao se fazer uma análise global de uma série de Balanços Energéticos, deve-se entender que as mudancas no comportamento tanto podem ser conseqüência das mudanças nos niveis das atividades econômicas quanto das mudanças estruturais do Setor Energético.

\section{Evoluçåo Global do Consumo Final Energético}

De acordo com a metodologia empregada no Balanço Energético Nacional (BEN), o consumo final energético no pais teve o seguinte comportamento: 


\begin{tabular}{lcccc}
\hline ESPECIFICAÇĀO & 1973 & 1979 & 1983 \\
\hline eletricidade & 15.928 & 31.582 & 41.069 \\
- derivados de petróleo e gás & $(21.2)$ & $(27.8)$ & $(33.6)$ \\
& 32.496 & 47.420 & 39.736 \\
outras fontes & $(43.1)$ & $(41.7)$ & $(32.5)$ \\
& 26.921 & 34.644 & 41.416 \\
TOTAL & $(35.7)$ & $(30.5)$ & $(33.9)$ \\
& 75.345 & 113.646 & 122.221 \\
& $(100.0)$ & $(100.0)$ & $(100.0)$ \\
\hline
\end{tabular}

Fonte: BEN-84

Destacam-se dois períodos com condicionantes bem dis tintos. De 1973 a 79 verificou-se um elevado crescimento da economia, o que representou um crescimento médio anual de $10,7 \%$ no valor do PIB, a preços constantes, e o in icio da Po. lítica Nacional de Energia, visando a substituição de derivados de petróleo, ainda que as ações concretas se mostrassem tímidas.

A partir de 1979, essas características se modificaram profundamente, com a economia praticamente sem apresentar crescimento, atingindo em 83 o mesmo valor do PIB, a preços constantes, de 1979 , e, por outro lado, com uma ação muito mais concentrada e firme, visando a redução do consumo de derivados de petróleo.

Nestes dois periodos, o consumo final energético no país teve as seguintes taxas de crescimento médio anual:

\begin{tabular}{l|r|c}
\hline \multicolumn{1}{c}{ ESPECIFICAÇĀO } & \multicolumn{2}{c}{ \% a.a. } \\
\hline eletricidade & $1973 / 79$ & $1979 / 83$ \\
\hline derivados de petróleo e gás & 12.0 & 6.8 \\
outras fontes & 6.5 & -4.3 \\
Total das fontes & 4.3 & 4.6 \\
\hline
\end{tabular}

Em termos departicipação observa-se um crescimento gradual do consumo da eletricidade, que aumentou cerca de 5 pontos percentua is em cada um dos periodos; os derivados de petróleo e gás mantêm a mesma participação no primeiro período, e a partir de 1979 decrescem 10 pontos.

É necessário contudo ponderar que, na contabilização dos fluxos energéticos correntemente empregada no Balanço Energético Nacional, convencionou-se utilizar o conceito de "tonelada equivalente de pe tróleo por substituiçăo (tep)". Assim, por exemplo, a energia elétrica tem o seu poder calorífico determinado pela quantidade de petróleo necessária para gerar $1 \mathrm{MWh}$, resultando na relação $1 \mathrm{MWh}=0,290$ tep.

Uma outra convenção, adotada por alguns paises, utiliza - conceito de "equivalência calórica" entre as formas de energia; por essa convenção as toneladas equivalentes de petróleo por substituição registradas no BEN como referentes à energia elétrica, ao álcool anidro e ao hidrato devem ser multiplicadas por um fator de conversão igual a $0.275,0.684 \mathrm{e}$ 0.782 , respectivamente.

Os mesmos Balanços Energéticos Nacionais apresentariam, entäo, a seguinte evolução do consumo final de energia, por essa convenção:

\begin{tabular}{lcccc}
\hline ESPECIFICAÇAO & 1973 & 1979 & 1983 \\
\hline eletricidade & 4.380 & 8.685 & 11.294 \\
- derivados de petróleo e gás & $(7.0)$ & $(9.7)$ & $(12.3)$ \\
& $(52.7)$ & 47.420 & 39.736 \\
- outras fontes & 24.847 & $34.4)$ & $(43.4)$ \\
& $(40.3)$ & $(37.9)$ & 40.474 \\
Total & 61.723 & 90.484 & 91.504 \\
& $(100.0)$ & $(100.0)$ & $(100.0)$ \\
\hline
\end{tabular}

BEN corrigido segundo a equivalência calórica.

Ainda neste caso, trata-se do suprimento energético às atividades econômicas, sem considerar, todavia, as diferenças entre toneladas equivalentes de petróleo de diferentes formas de energia quando consumidas por um mesmo equipamento de consumo final, isto é, não se levam em conta as eficiências energéticas desses equipamentos, que variam conforme a forma empregada; assim, por exemplo, o consumo final num fogão doméstico varia se é utilizado 1 tep de GLP, de lenha ou de eletricidade.

Isto leva ao conceito de Balanço de Energia Útil, que é a quantidade de energia sob as formas de calor de processo, força motriz, iluminaçăo, etc. que se convertem em serviço e que permitem visualizar as quantidades de energia que se devem ofertar internamente para se chegar a um trabalho desejado.

A relação entre o consumo final de energia (pela equivalência calórica) e a energia útil, para o ano de 1983, é indicada a seguir:

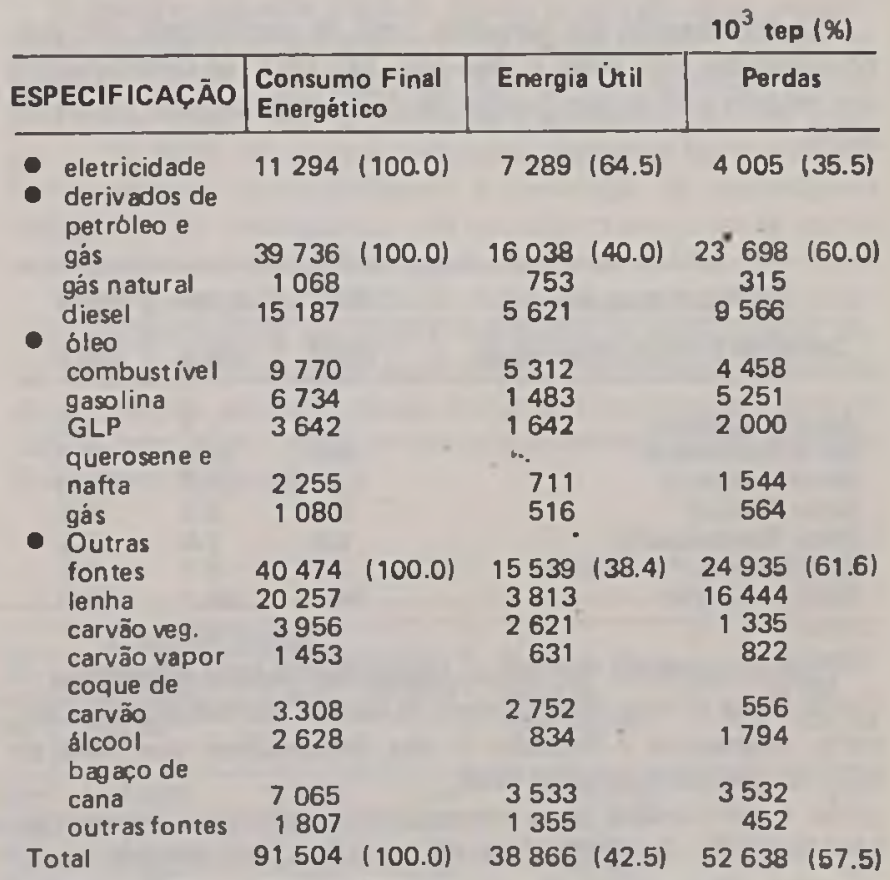

Fonte: Balanço de Energia Util

Verifica-se, pelo quadro, que a eletricidade é uma das formas de energia utilizada com menor perda dentre dos energéticos. A destinaçðo útil da eletricidade neste ano foi estimado em $60 \%$ para força motriz, $16 \%$ para calor de processo, $15 \%$ para aquecimento direto, $3 \%$ para iluminação, $2 \%$ para eletroquímica e $4 \%$ para outros fins. Novamente o valor relativamente baixo da iluminaçðo resulta da eficiência energética atribuída a uma lámpada (de 4 a 15\%). 
Quando utilizado este conceito de energia útil, a estrutura do Balanço Energético Nacional apresenta uma nova configuração. Se ele for aplicado em relação ao BEN corrigido pela equivalência calórica, ter-se-á o seguinte comportamento do consumo final de energia:

\begin{tabular}{l|c|c|c} 
& \multicolumn{3}{c}{$10^{3}$ tep (\%) } \\
\hline \multicolumn{1}{c|}{ ESPECIFICAC̄ĀO } & $1973^{*}$ & $1979^{*}$ & 1983 \\
\hline - eletricidade & 2.903 & 5.556 & 7.289 \\
- derivados de petróleo e gás & $(11.2)$ & $(15.6)$ & $(18.8)$ \\
& 12.479 & 18.241 & 16.038 \\
- outras fontes & $(47.9)$ & $(51.1)$ & $(41.3)$ \\
\hline Total & 10.634 & 11.848 & 15.539 \\
\hline & 26.016 & 35.645 & 38.866 \\
& & & $(100.0)$ \\
\hline
\end{tabular}

Fonte: Balanço de Energia Útil - BEU

* Foi adotada uma hipótese de que as eficiências médias de utilização das fontes de energia não se alterariam de 1973 a 1983, sendo então utilizados os dados da pesquisa feita em 83; isto implica na manutenção dos rendimentos energéticos dos equipamentos, como também da participação nas desti. nações das formas de energia útil consideradas.

\section{II- Evolução do Consumo Final Energético por Setor Eco- nômico}

Na distribuição do consumo final de eletricidade são preponderantes, em todo o período 1973/83, as participações dos setores industriais (acima de $50 \%$ ) e residencial (cerca de $20 \%)$.

(\%)

\begin{tabular}{l|r|r|r}
\hline \multicolumn{1}{c|}{ ESPECIFICAÇÃO } & 1973 & 1979 & 1983 \\
\hline Consumo Final de Eletricidade & 100.0 & 100.0 & 100.0 \\
\hline & & & \\
Setor Energético & 1.4 & 1.7 & 1.7 \\
Setor Residencial & 19.9 & 19.5 & 21.0 \\
Setor Comercial & 13.3 & 11.7 & 11.8 \\
Setor Püblico & 9.7 & 8.9 & 9.1 \\
Setor Agropecuário & 0.9 & 1.4 & 2.3 \\
Setor Transp. Ferroviário & 0.1 & 0.7 & 0.7 \\
Setor Industrial & 54.7 & 56.1 & 53.4 \\
\hline
\end{tabular}

Especificamente no Setor Industrial, alguns subsetores Ferro Gusa e Aço, não ferrosos e outros da Metalurgia, Química, Alimentos e Bebidas - são responsảveis por mais de $50 \%$ do consumo setorial final.

As modificações mais importantes ocorreram em relação à participação da eletricidade no consumo final de cada setor, e foram decorrentes de alterações no ritmo das atividades econômicas e da execução da Política Nacional de Energia, que visou à substituição de derivados de petróleo.

Para melhor avaliação dessas modificaçర̃es, classificaram-se os Setores Econômicos segundo sua relevância dentro do consumo final de eletricidade e quanto à importância da eletricidade para o suprimento energético do setor. Tomando-se como referência o Balanço de Energia Útil de 1983, ter-se-á então:

\begin{tabular}{|c|c|c|c|}
\hline ESPECIFICACCĀO & 1973 & 1979 & 1983 \\
\hline Setor Industrial & 100.0 & 100.0 & 100.0 \\
\hline - Cimento & 5.3 & 4.2 & 3.2 \\
\hline - Ferro Gusa e Aço & 10.7 & 12.9 & 11.5 \\
\hline - Ferro-Ligas & 3.2 & 3.6 & 4.5 \\
\hline - Mineração/Pelotizado & 2.5 & 3.4 & 5.2 \\
\hline - Não Ferrosos/Outros da Metalurgia & 19.0 & 18.0 & 16.9 \\
\hline - Quimica & 13.1 & 12.6 & 13.2 \\
\hline - Alimentos e Bebidas & 9.0 & 8.7 & 10.0 \\
\hline - Textil & 8.9 & 6.5 & 5.4 \\
\hline - Papel e Celulose & 6.7 & 7.2 & 7.3 \\
\hline - Cerâmica & 2.3 & 2.1 & 4.1 \\
\hline - Outros & 19.3 & 20.8 & 18.7 \\
\hline
\end{tabular}

\begin{tabular}{l|l|l}
\hline ESPECIFICAÇÃO & $\begin{array}{l}\text { Eletricidade não é pre- } \\
\text { dominante no consu- } \\
\text { mo de energia Útil }\end{array}$ & $\begin{array}{l}\text { Eletricidade é pre- } \\
\text { dominante no con- } \\
\text { sumo de energia Útil }\end{array}$ \\
\hline $\begin{array}{l}\text { Representam menos } \\
\text { de } 5 \% \text { de consumo } \\
\text { final de eletricidade }\end{array}$ & A \\
$\begin{array}{l}\text { Representam mais } \\
\text { de } 5 \% \text { do consu- } \\
\text { mo final de eletri- } \\
\text { cidade }\end{array}$ & C & D \\
\hline
\end{tabular}

Em seguida são sumariamente comentados os crescimentos do consumo de eletricidade, por Setor Econômico, tomando-se por base os periodos de 1973 a 79 e de 1979 a 83;

\section{GRUPO "D"}

- Setor Comercial - apresenta taxas significativas de crescimento, de $9.6 \%$ a.a., no periodo $1973 / 79$, e de $7.4 \%$ a.a., no periodo de $1979 / 83$, tendo concorrido para tanto a implantação de "Shopping.Center" e a ampliação das redes hoteleira e hospitalar, todos fazendo uso intensivo de refrigeração e iluminação. A eletricidade progressivamente aumentou sua participação a partir de 1973 , com o consumo de derivados de petróleo decrescendo no segundo periodo.

- Setor Público - todos os energéticos vêm crescendo a taxas bastante elevadas, sendo que a eletricidade cresceu a $10.0 \%$ a.a. e $8.1 \%$ a.a. respectivamente nos dois periodos considerados; destaque-se a participação da eletricidade na energia útil consumida em 83 , que foi da ordem de $80 \%$.

- Setor Industrial: Não Ferrosos e Outros da Metalurgia é um setor onde o crescimento da eletricidade praticamente se deu todo em 1983, o que se deve principalmente à entrada em operação dos contratos com vistas ao emprego da eletro. termia.

\section{GRUPO "C"}

- Setor Residencial - O consumo de energia elétrica resi. dencial foi o que mais cresceu nos periodos considerados 
(11.5\% a.a. e 9.0\% a.a.), sendo a maior parcela da destinação útil relativa à força motriz e calor de processo. Deve também ser ressaltado que o consumo médio domiciliar mantém-se estável, a partir de 1979 (1.6 MWh/domicílio). O consumo de eletricidade só não é preponderante em função da lenha que se consome no meio rural, em bases não comerciais.

- Setor Industrial: Ferro Gusa e Aço-depois de um elevado crescimento do consumo da ele tricidade (16.6\% a.a.) no primeiro período (seguido de perto pelo consumo coque de carvão mineral e carvão vegetal), no periodo seguinte registra-se uma taxa apenas modesta de crescimento ( $2.1 \%$ a.a.), perdendo a eletricidade importância para aqueles dois outros energéticos. Outro fato a destacar é a baixa eficiência média de utilização da eletricidade no setor, basicamente empregada para aquecimento direto.

- Setor Industrial: Alimentos e Bebidas - é um setor tradicionalmente grande consumidor de eletricidade, onde seu uso vem crescendo a taxas elevadas (de $12.5 \%$ a.a. e $8.8 \%$ a.a. nos períodos indicados) e sua participação só é inferior ao do bagaço de cana.

\section{GRUPO "B"}

- Setor Industrial: Ferro-Ligas - também este é um setor cujo consumo de eletricidade cresceu a taxas elevadas durante os dois períodos (respectivamente, $15.4 \%$ a.a. e $8.8 . \%$ a.a.).

\section{GRUPO "A"}

- Setor Energético - neste setor as áreas grandes consu.nidoras são as Refinarias e Destilarias, sendo reduzido o consumo de eletricidade (cerca de $3.6 \%$ do consumo de energia útil).

- Setor Agropecuário - o consumo de eletricidade vem crescendo a taxas muito elevadas desde 1973, em torno de $20.0 \%$ a.a., sendo seu uso basicamente destinado a força motriz.

- Setor Transportes - Ferroviário - de um crescimento reduzido no primeiro período, o consumo de eletricidade au. mentou significativamente no segundo periodo $(9,9 \%$ a.a.), para o que concorreu a entrada do Metrô em operação.

- Setor Industrial - Cimento - o fato marcante do consumo energético nesse setor é a adesão ao programa de substituição do óleo combustivel pelo carvão mineral e vegetal; o consumo de eletricidade registra um declinio no perlodo $1979 / 83$.
- Setor Industrial: Mineração e Pelotização - verifica-se um grande crescimento do consumo de eletricidade desde 1973 (cerca de $18.0 \%$ a.a.), sobretudo na indústria de mineração, assim como se verifica o início do emprego do carvão vegetal na indústria de pelotização, em detrimento do consumo de derivados de petróleo, em ambos subsetores.

- Setor Industrial - Química - a eletricidade e o gás são as duas fontes de maior crescimento neste setor; as taxas de crescimento da eletricidade foram de $19,7 \%$ a.a., de 1973 a 1979 , e de $6.5 \%$ a.a, no periodo seguinte.

- Setar Industrial - Têxtil - o consumo de eletricidade vem oscilando cerca de $10 \%$ desde 1979, atingindo em 1983 um nivel abaixo de 1979.

- Setor Industrial: Papel e Celulose - os principais substitutos para o óleo combustivel têm sido a lenha e o carvão mineral; a eletricidade teve um crescimento alto no primeiro periodo (14.5\% a.a.) e modesto depois (5.6\% a.a.), participando com $30.0 \%$ da energia útil em 1983.

- Setor Industrial - Cerâmica - é um setor onde o consumo de eletricidade, que já vinha crescendo a altas taxas de 1973 a 79 (cerca de $11.7 \%$ a.a.), teve seu crescimento mais que dobrado de 1979 a 83; a eletricidade representou em 1983, $30.0 \%$ da energia útil consumida.

- Outros Setores - Industriais - nestas indústrias, a eletricidade vem ganhando participação desde 1973, sendo o único consumo que cresceu no período $1979 / 83$, ainda que a uma taxa modesta de $2.3 \%$ a.a.

\section{Dados Comparativos Internacionais}

O quadro seguinte mostra alguns niveis de nossa eletrificação comparativamente com os de outros paises e regiōes da América Latina, extraídos dos Balanços Energéticos Nacionais consolidados pela Organização Latinoamericana de Energia - OLADE. Os valores indicados, inclusive para o Brasil, foram aqueles correspondentes à convenção de equivaléncia calórica e, por conseguinte, não coincidem exatamente com a publicação do Balanço Energético Nacional (BEN).

Destaca-se a singularidade do Brasil no que respeita à absoluta predominância da origem hidráulica da eletricidade. Pelas razões anteriormente explicadas, a participação é função da convenção adotada, sendo maior se considerada a energia ítil, e bem maior ainda se adotada. a convenção do Balanço Energético Nacional.

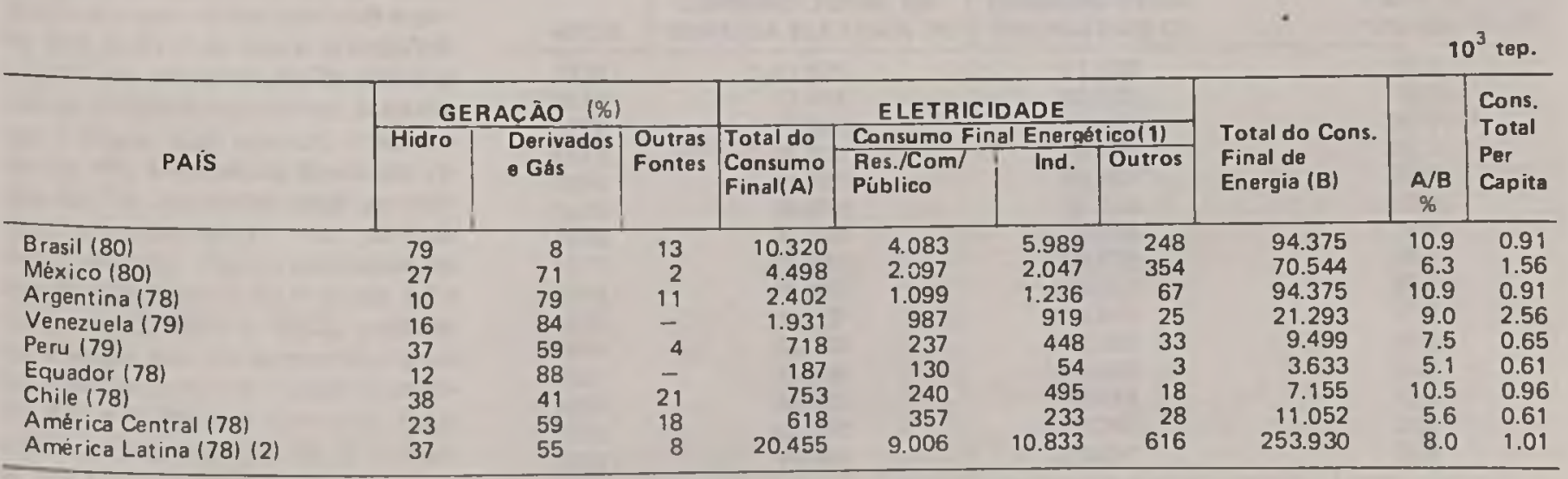

1 - Pela convencão da Olade não se inclui o autoconsumo do Setor Energético.

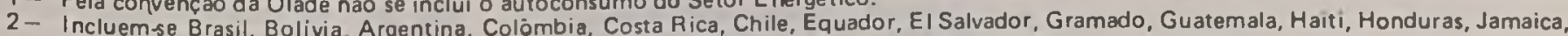
México, Nicarágua, Panamá, Peru. República Dominicana, Suriname, Trinidade, Tobago, Uruguai e Venezuela. 
ANEXO 1

\begin{tabular}{|c|c|c|c|}
\hline \multicolumn{4}{|c|}{$\begin{array}{l}\text { CONSUMO DE ENERGIA ÚTIL ESTIMADO PARA O } \\
\text { ANO DE } 1983 \\
10^{3} \text { tep }(\%)\end{array}$} \\
\hline ESPECIFICAÇĀO & Eletricidade & $\begin{array}{c}\text { Derivados de } \\
\text { Petróleo e Gás }\end{array}$ & $\begin{array}{l}\text { Outras } \\
\text { Fontes }\end{array}$ \\
\hline $\begin{array}{l}\text { Comercial } \\
\text { Público } \\
\text { Ind. não Ferrosos e } \\
\text { Outros da Metalurgia }\end{array}$ & $\begin{array}{c}\text { GRUPO "D' } \\
571(62.3) \\
490(80.8) \\
599(76.6)\end{array}$ & $\begin{array}{c}286(31.2) \\
102(16.7) \\
65(8.3)\end{array}$ & $\begin{array}{r}59(6.5) \\
20(3.3) \\
118(15.1)\end{array}$ \\
\hline $\begin{array}{l}\text { Residencial } \\
\text { Ind. Ferro Gusa e Aço } \\
\text { Ind. Alimentos e } \\
\text { Bebidas }\end{array}$ & $\begin{array}{c}\text { GRUPO “"C" } \\
1.369(32.4) \\
349(5.7) \\
516(12.5)\end{array}$ & $\begin{array}{r}1.522(36.0) \\
637(10.5) \\
708(17.2)\end{array}$ & $\begin{array}{l}1.329(31.6) \\
5.112(83.8) \\
2.890(70.3)\end{array}$ \\
\hline Ind. Ferro-Ligas & $\begin{array}{c}\text { GRUPO "'B" } \\
143(62.8)\end{array}$ & - & $85(37.2)$ \\
\hline $\begin{array}{l}\text { Energético } \\
\text { Agropecuário } \\
\text { Transporte Ferroviário } \\
\text { Indústria Cimento } \\
\text { Indústria Mineração e } \\
\text { Politização } \\
\text { Indústria Qulmica } \\
\text { Indústria Têxtll } \\
\text { Ind. Papel e Celulose } \\
\text { Indústria Cerâmica } \\
\text { Outras Indústrias }\end{array}$ & \begin{tabular}{|c|} 
GRUPO “A"A \\
$170(3.6)$ \\
$221(13.0)$ \\
$75(27.9)$ \\
$171(18.9)$ \\
$198(38.7)$ \\
$680(25.7)$ \\
$277(36.2)$ \\
$389(30.0)$ \\
$194(30.0)$ \\
$877(60.3)$
\end{tabular} & $\begin{array}{r}1.827(38.7) \\
820(48.5) \\
192(71.4) \\
227(25.0) \\
287(56.0) \\
1.852(70.0) \\
387(50.6) \\
483(36.0) \\
141(21.8) \\
400(27.5)\end{array}$ & $\begin{array}{c}2.729(57.7) \\
650(30.5) \\
2(0.7) \\
509(56.1) \\
27(5.3) \\
115(4.3) \\
100(13.2) \\
471(34.0) \\
312(48.2) \\
177(12.2)\end{array}$ \\
\hline
\end{tabular}

ANEXO 2

\begin{tabular}{|c|c|c|c|c|c|c|}
\hline \multicolumn{7}{|c|}{$\begin{array}{l}\text { A DESTINACAO UTIL DA ELETRICIDADE, POR SETOR } \\
\text { CONSUMIDOR, NO ANO DE } 1883 . \\
(\%)\end{array}$} \\
\hline ESPECIFICACAO & $\begin{array}{l}\text { Forca } \\
\text { Motrly }\end{array}$ & Caloe de & $\begin{array}{l}\text { Aqued. } \\
\text { minto } \\
\text { diruse }\end{array}$ & $\begin{array}{l}\text { llumina } \\
\text { ro }\end{array}$ & \begin{tabular}{|l|} 
Elotro- \\
Ouimina
\end{tabular} & $\begin{array}{l}\text { Outre } \\
\text { Fonter }\end{array}$ \\
\hline $\begin{array}{l}\text { Comarclal } \\
\text { Publlco } \\
\text { Ind. n } \\
\text { Outo Farrasos de Metalurgla }\end{array}$ & $\begin{array}{c}\text { Q AUPO } \\
52.0 \\
68.8 \\
48.6\end{array}$ & $\begin{array}{l}0.7 \\
0.0 \\
1.8\end{array}$ & $\begin{array}{r}29.8 \\
8.2 \\
30.7\end{array}$ & $\begin{array}{r}17.7 \\
220 \\
0.0\end{array}$ & $\begin{array}{c}- \\
18.8\end{array}$ & $\bar{z}$ \\
\hline $\begin{array}{l}\text { Realdenclal } \\
\text { Ind. Farro Guat a Aggo. }\end{array}$ & $\begin{array}{c}\text { OAUPO } \\
30.7 \\
1.7\end{array}$ & $\begin{array}{l}4.0 \\
0.6\end{array}$ & 97. & $\begin{array}{l}2.0 \\
0.0\end{array}$ & $\overline{0.0}$ & 14.3 \\
\hline Ind. Ferro-பgea & 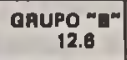 & - & 87.4 & 0.0 & 0.0 & 0.0 \\
\hline 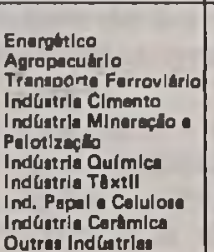 & $\begin{array}{c}\text { OAUPO “A } \\
96.5 \\
94.6 \\
1000 \\
93.6 \\
71.2 \\
83.2 \\
93.8 \\
88.7 \\
78.8 \\
87.8\end{array}$ & $\begin{array}{l}3.5 \\
1.0 \\
0.0 \\
\overline{0.3} \\
4.3 \\
2.5 \\
0.0 \\
2.2\end{array}$ & $\begin{array}{r}\overline{3.2} \\
\overline{5.3} \\
29.3 \\
3.5 \\
0.6 \\
0.8 \\
24.2 \\
8.1\end{array}$ & $\begin{array}{l}\overline{0} \\
\overline{0.0} \\
0.0 \\
0.0 \\
0.5 \\
0.6 \\
0.6 \\
0.0 \\
0.8\end{array}$ & $\begin{array}{l}\bar{z} \\
\bar{z} \\
\overline{6} .3 \\
\bar{z} \\
=\end{array}$ & $\begin{array}{l}\overline{1.2} \\
\overline{0.5} \\
0.5 \\
0.5 \\
1.0 \\
0.6 \\
0.0 \\
1.2\end{array}$ \\
\hline
\end{tabular}

\section{BIBLIOGRAFIA}

Ministério das Minas e Energia - "Balanço Energético Nacional" 1984.

Ministério das Minas e Energia - "Balanço de Energia Ütil" (dez./84).

Ministério das Minas e Energia - "Balanço do Seter Energético" (85).

OLADE - "Balnços Energéticos de America Latina" - (nov./81) 